05

\title{
Неразрушающий контроль поверхности, слоев и концентрации носителей заряда в подложках и структурах SiC
}

\author{
() А.В. Марков, М.Ф. Панов, В.П. Растегаев, Е.Н. Севостьянов, В.В. Трушлякова \\ Санкт-Петербургский государственный электротехнический университет „ЛЭТИ“, \\ 197376 Санкт-Петербург, Россия \\ e-mail: 19_panov_59@mail.ru
}

Поступило в Редакцию 19 декабря 2018 г.

В окончательной редакции 19 декабря 2018 г.

Принято к публикации 6 июня 2019 г.

Неразрушающими бесконтактными методами исследованы карбидокремниевые подложки и эпитаксиальные структуры. Параметры нарушенного поверхностного слоя и шероховатости определены методами эллипсометрии и атомно-силовой микроскопии. Концентрация свободных носителей заряда определена методом ИК спектроскопии. Толщины в многослойной эпитаксиальной структуре на $\mathrm{SiC}$ определены с помощью ИК спектроскопии и растровой электронной микроскопии.

Ключевые слова: слой, отражение, интерференция, шероховатость, эллипсометрия.

DOI: $10.21883 / J T F .2019 .12 .48484 .435-18$

В технологическом цикле создания приборов на основе карбида кремния и постростового контроля готовых пластин с эпитаксиальными слоями карбида кремния на карбидокремниевой подложке важнейшими операциями являются, во-первых, контроль поверхности подложек, во-вторых, контроль концентрации свободных носителей заряда в подложках, в-третьих, контроль толщин эпитаксиальных слоев приборных структур. Набольшей оперативностью среди группы известных способов контроля характеризуются неразрушающие бесконтактные методы. В настоящей работе продемонстрирована эффективность контроля параметров подложек и структур на основе $\mathrm{SiC}$ (политип 4H) такими бесконтактными методами, как отражательная эллипсометрия, ИК спектроскопия, атомно-силовая микроскопия, растровая электронная микроскопия.

Важнейшим бесконтактным методом исследования поверхности является оптическая микроскопия [1]. Но она не применима к исследованию шероховатости при высоких классах обработки поверхности, как позволяющая визуализировать объекты с размером только более длины волны. Для измерения толщин с ее помощью требуется осуществление фокусировки света на обеих границах слоя, и следовательно, требуют заметной разницы показателей преломления слоя и подложки. Эллипсометрия [2,3] характеризуется высокой точностью и чувствительностью. Она эффективна при толщинах от десятков ангстрем до приблизительно микрона, иначе говоря, чувствительна к слоям нанометровых толщин. Атомно-силовая методика также способна контролировать рельеф поверхности на субнанометровом уровне [4]. ИК спектроскопическая методика применима, прежде всего, при определении концентрации свободных носителей заряда $[5,6]$. Спектроскопия используется также и при определении толщин слоев по спектральной интерференции в слоях, толщина которых лежит в диапазоне от единиц до сотен микрон, и наблюдение ее возможно при совпадении реальных составляющих показателей преломления $\mathrm{n}$ слоя и подложки, но различии мнимых, т.е. их коэффициентов экстинкции $k$ [7]. (Под комплексным показателем преломления понимают $N=n-i k$.)

\section{ИК спектроскопия, эллипсометрия, атомно-силовая микроскопия: контроль глубины нарушенного слоя и шероховатости}

Для получения поверхности карбидокремниевой подложки, пригодной для дальнейших производственных операций, необходимо выполнение шлифовки и полировки поверхности. После любой абразивной обработки в результате ударного воздействия зерен на обрабатываемую поверхность остается нарушенный слой той или иной глубины. Нарушенный слой оказывает существенное влияние на электрофизические характеристики готовых полупроводниковых приборов. Из-за этого глубину нарушенного слоя стараются свести к минимуму перед дальнейшими этапами производства.

Качество обработки поверхности подложек $\mathrm{SiC}$ контролировалось тремя бесконтактными оптическими методами.

Пластины, имеющие разное качество обработки, исследовались методом ИК спектроскопии на приборе Nikolet-6700 при диаметре луча 2-3 mm. На рис. 1 представлены спектры отражения при нормальном падении света для трех пластин: 1 - непосредственно после резки кристалла, 2 - после шлифовки пастой с размером зерна $7-5 \mu$ т и $3-$ после полировки пастой с размером зерна 1-0 (менее $1 \mu \mathrm{m})$. Класс обработки 


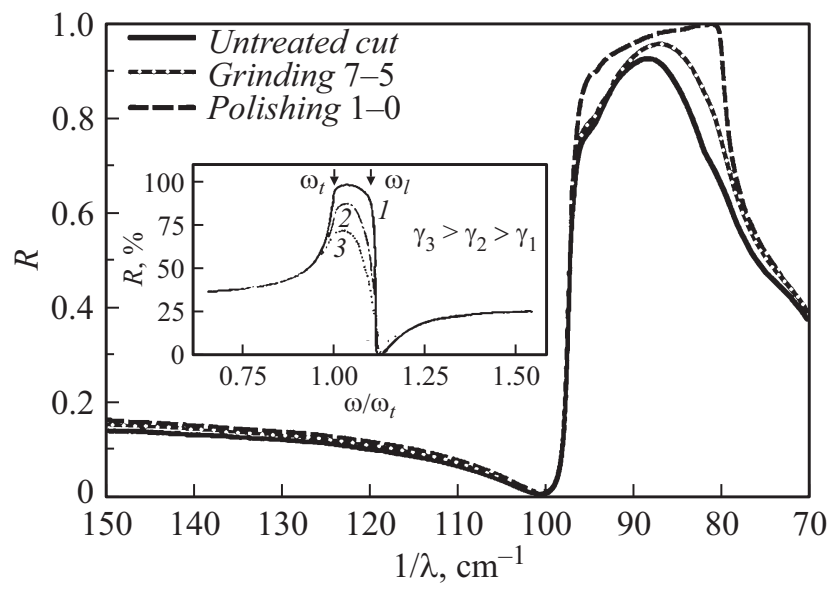

Рис. 1. Спектры коэффициента отражения подложек с разным качеством обработки поверхности.

поверхности влияет на форму спектральных кривых. Все спектры отражения имеют форму, качественно близкую к форме теоретического спектра, полученного в рамках одноосцилляторной модели.

В области аномальной дисперсии - в полосе „остаточных лучей“ (между частотами колебаний поперечного и продольного оптических фононов $\omega_{t}$ и $\left.\omega_{l}\right)$, где теоретический показатель преломления должен быть чисто мнимый, а коэффициент отражения равным единице, наблюдается характерный максимум отражения. Причем форма максимума тем более близка к теоретической („квадратной“), чем качественнее обработана поверхность. С увеличением „развитости“ поверхности делается меньше коэффициент отражения и более сглаженным становится максимум его экспериментального спектра в полосе „остаточных лучей“. Аналогичные изменения теоретического спектра происходят в теории дисперсии при увеличении параметра материала Г (см. параметр $\Gamma_{T}$ в формуле (1)), называемого коэффициентом затухания фононных колебаний [8]. (Изменение теоретического спектра при варьировании коэффициента затухания фононов представлено на вставке рис. 1.) Логично предположить, что такой фактор, как большая толщина нарушенного слоя, является фактором затухания фононов, что и объясняет изменение формы экспериментального спектра в области остаточных лучей.

При исследовании глубины нарушенного слоя методом отражательной эллипсометрии применялась модель, рассматривающая нарушенный слой (и, в частности, шероховатость подложки) как наличие поверхностного слоя с показателем преломления, отличающегося от объемного значения для $\mathrm{SiC}$ в меньшую сторону. Данное приближение не учитывает возможного наличия градиента показателя преломления между нарушенным слоем и объемом пластины, но характеризуется простотой и оперативностью. Численные значения показателя преломления и толщины нарушенного слоя для различной степени обработки поверхности получены из эллипсо- метрических измерений методом Холмса [2]. Этот метод основан на утверждении о вещественности толщины при решении комплексного основного уравнения эллипсометрии. Толщина нарушенного слоя в зависимости от размера зерна и метода обработки $(10-7 \mu \mathrm{m}-$ шлифовка, 5-3, 1-0, 0.25-0 $\mu \mathrm{m}$ - полировка [9]) составляла от нескольких сотен до нескольких десятков ангстрем. Эллипсометрические измерения проводились на длине волны $0.633 \mathrm{~nm}$ при диаметре луча около $2 \mathrm{~mm}$. Номограмма эллипсометрических углов $\Psi$ и $\Delta$ для нарушенного слоя с характерным для него показателем 2.4 на подложке $\mathrm{SiC}$ приведена на рис. 2. Там же на встроенном графике, для примера, показана номограмма для структуры $\mathrm{Si}-\mathrm{SiO}_{2}$. На номограммах указаны точки, которые соответствуют толщинам нарушенных слоев. Номограммы показывают, что нанослои исследуемых структур „SiC-нарушенный слой“ не попадают в ситуацию с высокой степенью неопределенности одного из эллипсометрических углов $(\Delta)$, в отличие от такой классической структуры, как $\mathrm{Si}-\mathrm{SiO}_{2}$ (линия номограммы для тонких слоев этой структуры почти параллельна оси угла $\Psi)$. Это подтверждает надежность и достоверность результатов эллипсометрического определения сверхтонких нарушенных слоев на карбиде кремния.

В табл. 1 представлены данные о размере зерна паст шлифовки и полировки и соответствующие средние по пластинам диаметром 5-7 cm результаты эллипсометрических измерений. Уменьшение толщины нарушенного слоя коррелирует с уменьшением размера зерна.

Шероховатость поверхности контролировалась с помощью метода атомно-силовой микроскопии (АСM). На рис. 3 представлены микрофотографии рельефа характерных участков поверхности трех пластин, подвергнутых шлифовке пастой с размером зерна 10-7 $\mu \mathrm{m}$ и полировке пастой с размером зерна $1-0 \mu \mathrm{m}$, а также

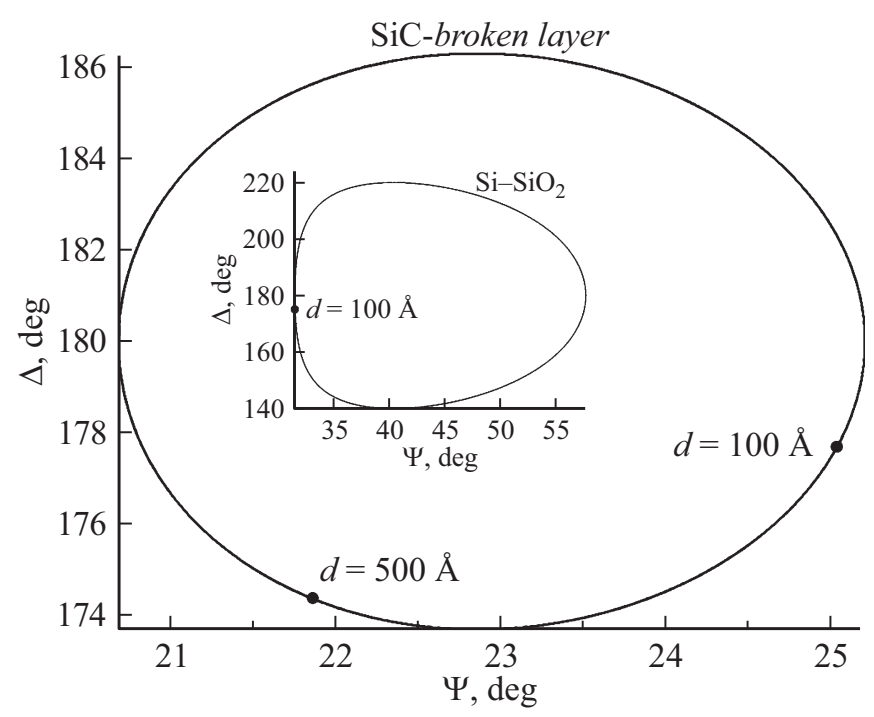

Рис. 2. Номограмма эллипсометрических углов $\Psi$ и $\Delta$ для нарушенного слоя на $\mathrm{SiC}$ и для структуры $\mathrm{Si}-\mathrm{SiO}_{2}$ для угла падения $50^{\circ}$. 
Таблица 1. Результаты эллипсометрических измерений для различных классов обработки поверхности подложек $\mathrm{SiC}$

\begin{tabular}{c|c|c}
\hline Размер зерна пасты, $\mu \mathrm{m}$ & Толщина слоя, $\AA$ & Показатель преломления слоя \\
\hline $10-7$ & 669 & 2.410 \\
$5-3$ & 452 & 2.440 \\
$1-0$ & 127 & 2.481 \\
$0.25-0$ (2 h обработки) & 105 & 2.486 \\
$0.25-0$ (4 h обработки) & 87 & 2.308
\end{tabular}
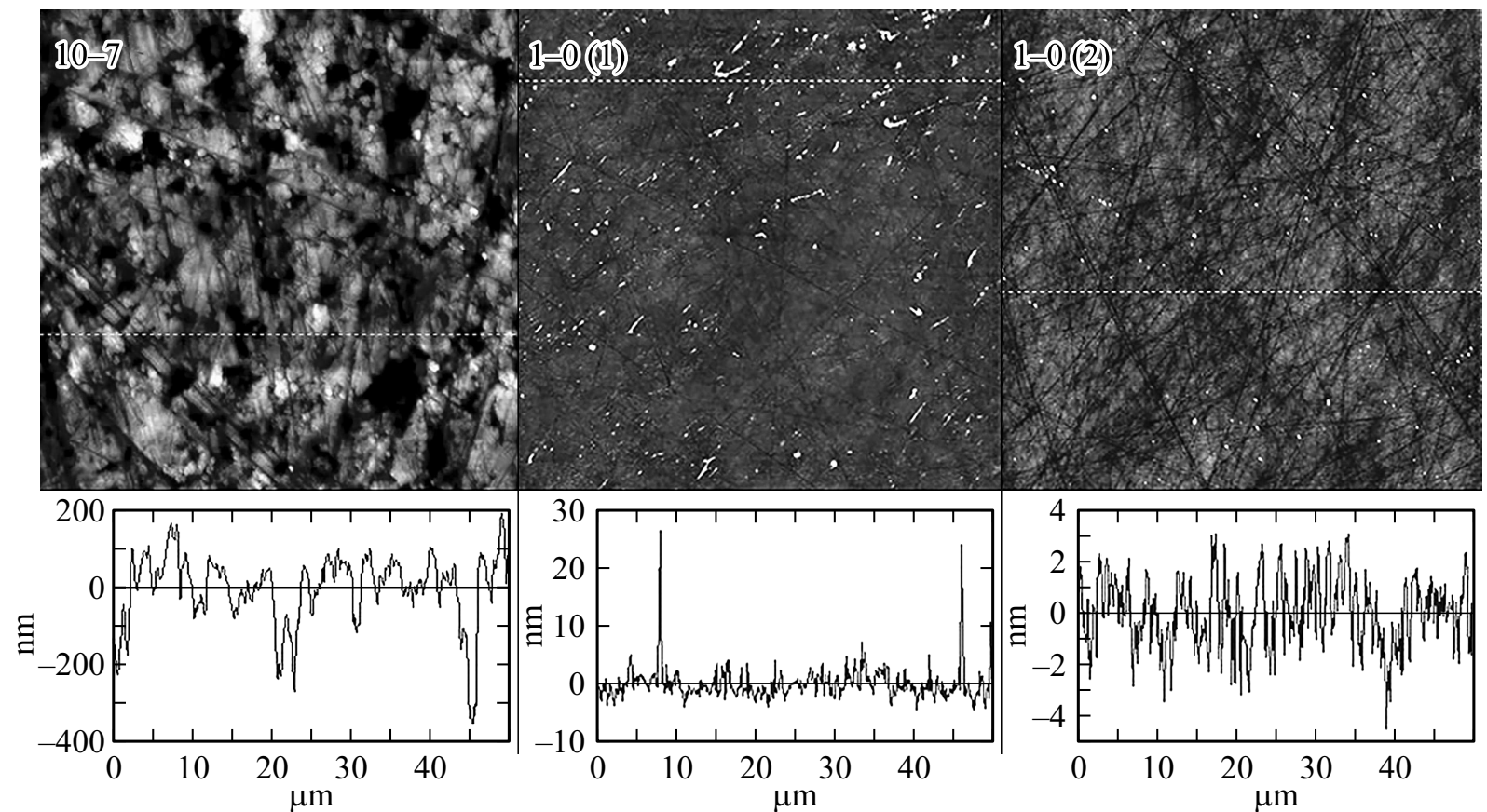

Рис. 3. Результаты исследования рельефа поверхности подложек методом АСМ.

профили рельефа поверхности в области указанных пунктиром сечений. На рис. 3 в разных масштабах приведены данные по двум подложкам после обработки пастой 1-0. Первая из них характеризуется большим разбросом размера шероховатости вследствие того, что присутствуют остатки алмазной полирующей пасты.

Толщина нарушенного слоя, представленная как рельеф поверхности, в целом коррелирует с толщиной нарушенного слоя, определенной эллипсометрическим методом. Однако имеет место небольшое, но систематическое расхождение результатов величины визуализированной шероховатости и эллипсометрически измеренной толщины нарушенного слоя. Для поверхности, обработанной шлифовкой (паста с зерном $10-7 \mu \mathrm{m}$ ), средняя толщина нарушенного слоя (по данным эллипсометрии) и глубина рельефа (шероховатость по данным ACM) имеют близкие величины - несколько сотен ангстрем, но шероховатость несколько больше эллипсометрически измеренной толщины нарушенного слоя. Для поверхностей же, подвергнутых дополнительной полировке (паста с зерном не более $1 \mu \mathrm{m}$ ), наоборот, эллипсометрически измеренная толщина нарушенного слоя превышает среднюю шероховатость. Связано это, очевидно, с тем, что в разной степени обработанные подложки характеризуются различной степенью неоднородности распределения показателя преломления по глубине. А эта неоднородность не учитывается в однослойной модели структуры.

\section{ИК спектроскопия: контроль концентрации свободных носителей заряда}

Определение концентрации свободных носителей заряда в подложке $\mathrm{SiC}$ политипа $4 \mathrm{H}$ выполнено с помощью обработки спектра отражения в области среднего и дальнего ИК диапазона. Для этого проводилось моделирование спектра отражения в диапазоне частот, включающем область остаточных лучей (область однофононного резонанса, для $\left.\mathrm{SiC}-1200-600 \mathrm{~cm}^{-1}\right)$ и область плазмонного резонанса (в $\left.\mathrm{SiC}-800-60 \mathrm{~cm}^{-1}\right)$. 
Таблица 2. Параметры подложек $\mathrm{SiC}$, определенные по спектрам отражения

\begin{tabular}{c|c|c|c}
\hline Образец & $1 / \lambda_{p}, \mathrm{~cm}^{-1}$ & $\gamma, \mathrm{s}^{-1}$ & $n, \mathrm{~cm}^{-3}$ \\
\hline$a$ & 180 & 400 & $7.08 \cdot 10^{17}$ \\
$b$ & 500 & 430 & $5.46 \cdot 10^{18}$
\end{tabular}

При моделировании спектра отражения использована классическая диэлектрическая функция, предполагающая, что вклады систем фотонов и электронов являются независимыми и аддитивными $[5,6,8]$

$$
\varepsilon(\omega)=\varepsilon_{\infty}\left[\frac{\omega_{L}^{2}-\omega^{2}-i \omega \Gamma_{L}}{\omega_{T}^{2}-\omega^{2}-i \omega \Gamma_{T}}-\frac{\omega_{p}^{2}}{\omega(\omega+i \gamma)}\right] .
$$

Здесь $\varepsilon_{\infty}-$ оптическая диэлектрическая постоянная; $\omega_{T}$ и $\omega_{L}$ - частота колебаний поперечных продольных фононов; $\omega_{p}$ - частота плазмонного резонанса; $\gamma-$ коэффициент рассеяния плазмонов; $\Gamma_{T}$ и $\Gamma_{L}-$ коэффициенты затухания оптических фононов с поперечной и продольной поляризациями. Первый член выражения для $\varepsilon$ характеризует вклад фононов и получен с помощью лоренцовской осцилляторной модели, а второй представляет собой вклад свободных носителей заряда и получен в теории Друде.

Коэффициент отражения при нормальном падении определяется как

$$
R(\omega)=\left|\frac{\sqrt{\varepsilon(\omega)}-1}{\sqrt{\varepsilon(\omega)}+1}\right|^{2} .
$$

Частота плазмонного резонанса в теории Друде связана с концентраций свободных носителей заряда $n$ соотношением

$$
\omega_{p}=\sqrt{\frac{4 \pi n e^{2}}{\varepsilon_{\infty} m^{*}}},
$$

где $m^{*}$ - эффективная масса свободных носителей заряда, для карбида кремния политипа $4 \mathrm{H}$, равная $2.7 \cdot 10^{-31} \mathrm{~kg}$.

Для политипа 4H карбида кремния диэлектрическая проницаемость в оптическом диапазоне $\varepsilon_{\infty}=6.78$, $\omega_{T}=797 \mathrm{~cm}^{-1} ; \omega_{L}=966.4 \mathrm{~cm}^{-1}$, а значения $\gamma, \Gamma_{T}, \Gamma_{L}$, $\omega_{p}$ зависят от концентрации свободных носителей заряда. Но так как в формирование спектра отражения изменение значений и $\Gamma_{T}$ и $\Gamma_{L}$ не вносят существенного вклада (вносят изменение в значение $R$ меньше одного процента), для упрощения вычислений они фиксировались: $\Gamma_{L}=6 \mathrm{~cm}^{-1}, \Gamma_{T}=6.5 \mathrm{~cm}^{-1}[10]$.

На рис. 4 приведены экспериментальные спектральные зависимости коэффициента отражения подложек карбида кремния с различным значением плазмонного резонанса (точечные линии), а также зависимости, полученные аппроксимацией (формулы (1), (2)) с использованием указанных выше параметров (сплошные линии). В случае низкой концентрации носителей (рис. 4, $a$ )
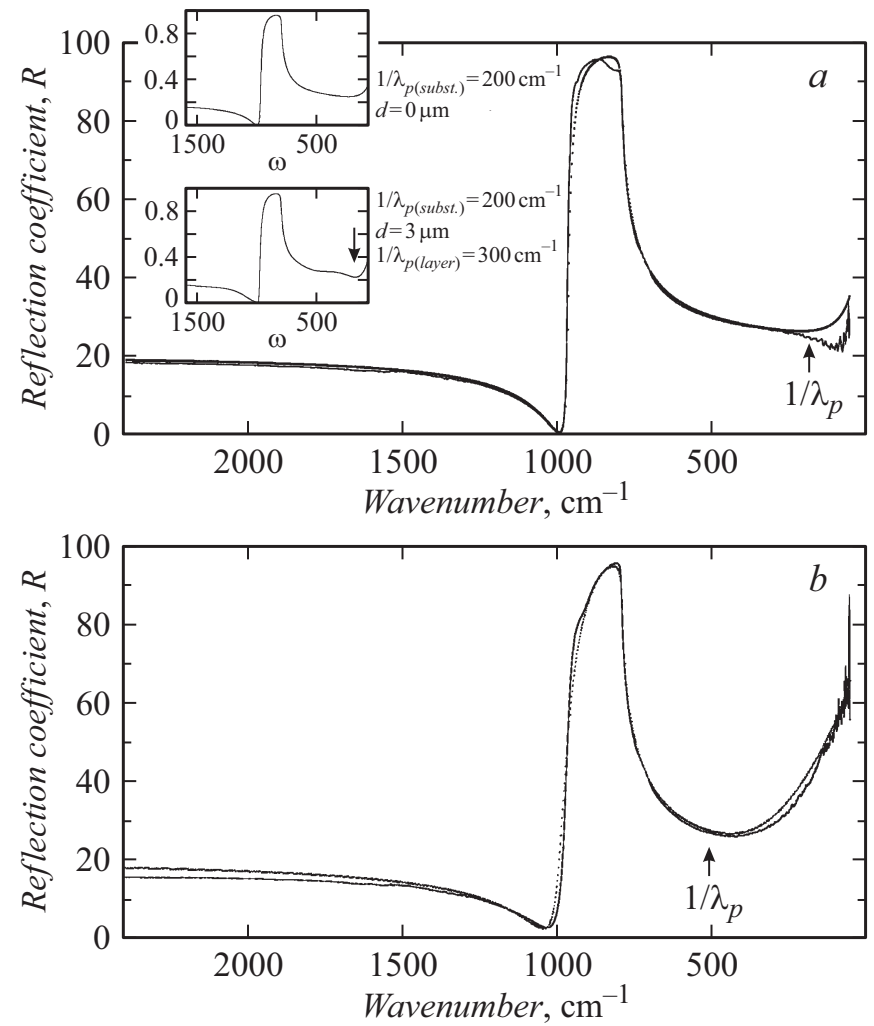

Рис. 4. Спектры отражения подложек $\mathrm{SiC}$ с низкой $(a)$ $\left(n=7.08 \cdot 10^{17} \mathrm{~cm}^{-3}\right)$ и высокой $(b)\left(n=5.46 \cdot 10^{18} \mathrm{~cm}^{-3}\right)$ концентрациями свободных носителей. На вставках - изменение теоретического спектра при „добавлении“ тонкого слоя толщиной $d$ на поверхность подложки. Спектры во вставках рассчитаны для подложки и слоя с плазмонными минимумами $1 / \lambda_{p}$, равными соответственно 200 и $300 \mathrm{~cm}^{-1}$.

спектральное положение частоты плазмонного резонанса практически совпадает с низкочастотным минимумом коэффициента отражения. В случае же высоких концентраций (рис. $4, b)$ этого совпадения нет, и определение значения $\omega_{p}$ возможно только с помощью аппроксимации. Определенные экспериментально параметры $\gamma$ и $\omega_{p}$ и рассчитанный с использованием формулы (3) параметр $n$ для исследованных подложек приведены в табл. 2 .

Спектральная зависимость на рис. $4, a$ отличается хорошим совпадением экспериментальной и подгоночной зависимостей, за исключением небольшого минимума вблизи $100 \mathrm{~cm}^{-1}$ (указано стрелкой со звездочкой). Одно из возможных объяснений - наличие тонкого карбидокремниевого слоя на поверхности с большей, чем в объеме, концентрацией носителей. Для подтверждения на вставке рис. 4, а приведены два теоретических спектра коэффициента отражения: $\mathrm{SiC}$ без слоя и со слоем, имеющим большее значение $1 / \lambda_{p}$ по сравнению с подложкой. При этом в виде дополнительного минимума в низкочастотной области проявляется спектральная интерференция в слое (указано стрелкой со звездочкой). 
Таблица 3. Технологические параметры исследованной эпитаксиальной структуры

\begin{tabular}{l|c|c|c|c|c}
\hline \multicolumn{1}{|c|}{ Элемент структуры } & $\begin{array}{c}\text { Подложка } \\
(1)\end{array}$ & $\begin{array}{c}\text { Слой } 1 \\
(2)\end{array}$ & $\begin{array}{c}\text { Слой } 2 \\
(3)\end{array}$ & $\begin{array}{c}\text { Слой } 3 \\
(4)\end{array}$ & $\begin{array}{c}\text { Слой } 4 \\
(5)\end{array}$ \\
\hline Тип проводимости & $p$ & $p^{+}$ & $p^{-}$ & $n^{-}$ & $n^{+}$ \\
Концентрация примеси, $\mathrm{cm}^{-3}$ & $\sim 10^{15}$ & $2 \cdot 10^{19}$ & $6 \cdot 10^{15}$ & $6 \cdot 10^{15}$ & $1 \cdot 10^{19}$ \\
Толщина, $\mu \mathrm{m}$ & - & 2.3 & 15 & 2
\end{tabular}

\section{ИК спектроскопия, растровая электронная микроскопия: контроль толщины слоев эпитаксиальных структур}

Карбид кремния в области ближнего ИК диапазона в спектральной области величиной от нескольких сотен до полутора тысяч обратных сантиметров характеризуется практически полной прозрачностью и мало меняющейся амплитудой спектральной интерференции в слоях [7]. Поэтому в этой области фазовые условия отражения на границах раздела между слоем и подложкой, а также между слоями, меняются очень слабо. К тому же в этой области у карбида кремния почти постоянен показатель преломления. Таким образом, для расчета толщин слоев карбида кремния применимо соотношение

$$
d=\frac{1}{2 n \Delta \sigma}
$$

где $\Delta \sigma-$ спектральное расстояние между соседними максимумами (минимумами) интерференции, а $n-$ показатель преломления слоя в указанном спектральном диапазоне.

В качестве примера рассматриваются результаты исследования приборной эпитаксиальной структуры, послойное описание которой по данным технологического процесса приведено в табл. 3 .

Технологические данные толщин слоев были проконтролированы с помощью растровой электронной микроскопии на приборе Quanta Inspect. Торец эпитаксиальной структуры, подготовленный шлифовкой, а также механической и химической полировкой, представлен на рис. 5. Толщины слоев, наблюдаемые на рис. 5, хорошо согласуются с данными табл. 3.

Спектр отражения структуры со стороны эпитаксиальных слоев приведен на рис. 6. В спектральной зависимости в ближней и средней ИК областях нашли отражение две визуально наблюдаемые интерференции: с малым периодом и огибающая с большим периодом биений (рис. 6). Проведено спектральное исследование участка периодической функции коэффициента отражения в диапазоне $1500-3000 \mathrm{~cm}^{-1}$ с использованием программы LabView. Спектральное исследование выполнялось путем проведения фурье-преобразования спектра отражения и использования формулы (4). Результат приведен на рис. 7. В данном случае частота колебаний функции спектральной интерференции есть величина,

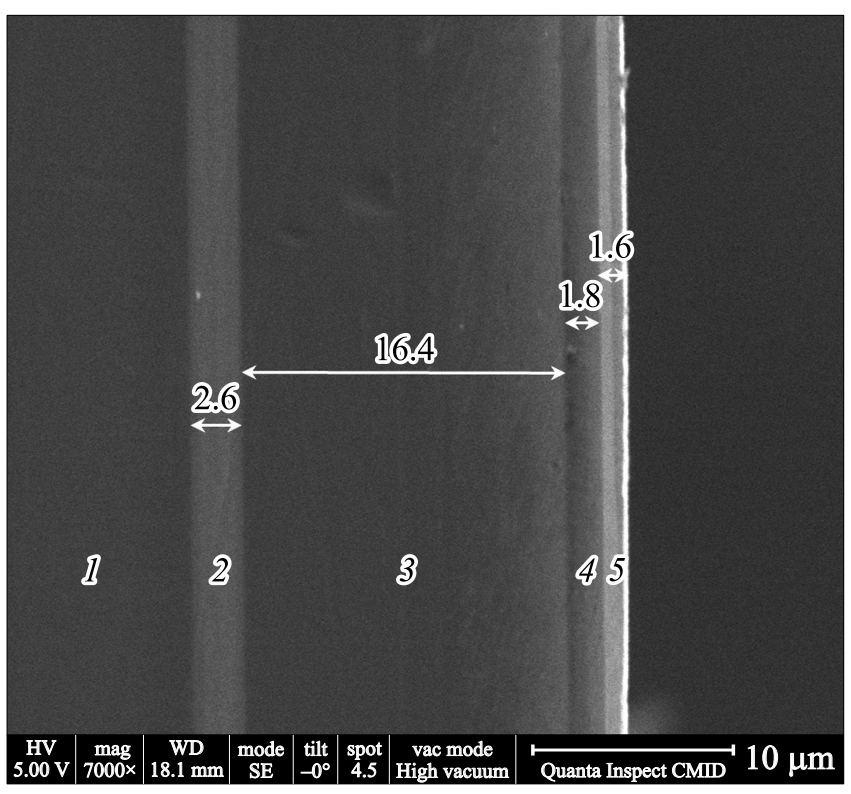

Рис. 5. Торец четырехслойной эпитаксиальной структуры на $\mathrm{SiC}$, наблюдаемый с помощью растровой электронной микроскопии: $1-$ подложка, $2-5-$ слои.

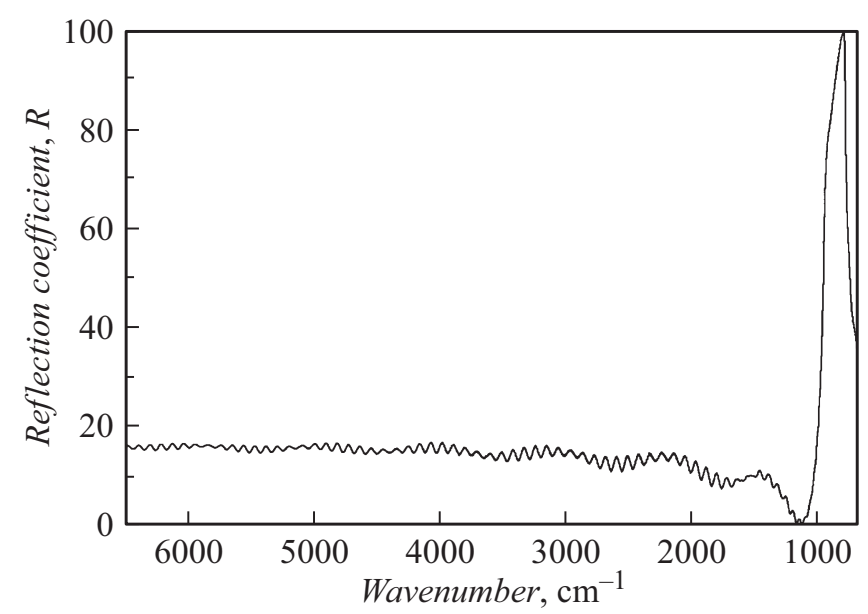

Рис. 6. ИК спектр отражения многослойной эпитаксиальной структуры на $\mathrm{SiC}$.

пропорциональная толщине слоя (слоев) структуры, и именно в толщинах слоев отградуирован график функции фурье-образа спектра. 


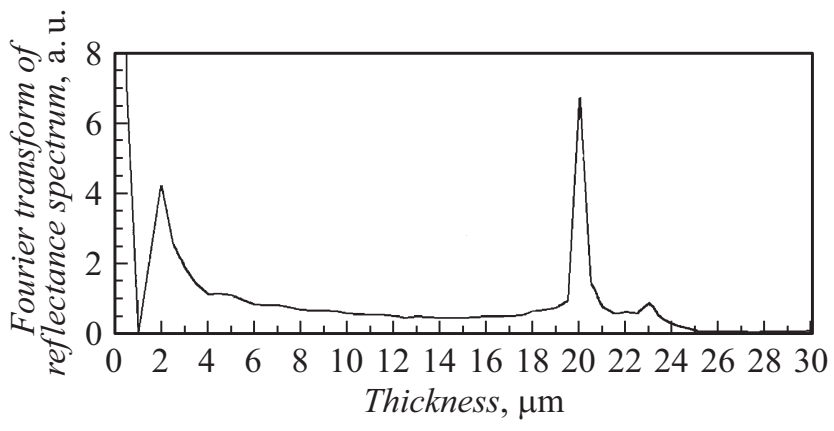

Рис. 7. Определение толщин слоев с помощью фурье-анализа ИК спектра отражения.

Частотный анализ спектра, дающий значения эпитаксиальных слоев данной структуры, показывает, что в спектральной интерференции проявились слои толщиной 20 и $2 \mu \mathrm{m}$. Логично предположить, что эти результаты приблизительно соответствуют суммарной толщине всех слоев, а также толщине сильно легированного верхнего слоя $\left(n^{+}\right.$с концентрацией $\left.1 \cdot 10^{19} \mathrm{~cm}^{-3}\right)$.

Структура эпитаксиального слоя отличается от структуры монокристаллической подложки, что создает соответствующую оптическую границу и приводит к наблюдению общеструктурной интерференции. А проявлению интерференции в отдельном тонком слое объяснение можно дать следующее. Как отмечено в работе [7], фазовая скорость распространения света в материале с ненулевой проводимостью зависит от последней через квадратичную поправку. По оценкам эта поправка вносит заметный вклад, позволяющий создать отражающую поверхность на границе слоев, лишь при концентрации свободных носителей заряда порядка $10^{18} \mathrm{~cm}^{-3}$ (и того же порядка концентрациях примеси) в материале карбида кремния $n$-типа. Для $p$-карбида кремния, легированного, например, алюминием, такая концентрация носителей достигается лишь при еще больших концентрациях примеси из-за требования более высокой величины ионизации примеси (неполная ионизация) и низкой величины подвижности носителей заряда (дырок). В результате, многослойную структуру, в которой отсутствуют $n^{+}$-слои, по спектральной интерференции можно наблюдать только как однородный материал.

В работе продемонстрирована характеризация подложек и эпитаксиальных структур несколькими бесконтактными методами, среди которых эллипсометрия, ИК спектроскопия, атомно-силовая микроскопия, растровая электронная микроскопия. Показаны возможности методов при определении структурных и электроннокинетических параметров субмикронных слоев и нанослоев.

\section{Финансирование работы}

Работа выполнена в рамках ОКР „Создание промышленного эпитаксиального производства карбидокремни- евых многослойных структур для отечественного электронного приборостроения“ (Шифр „Ресурс-К“') по заказу Минобрнауки, проводимой как IX очередь Комплексного проекта по созданию высокотехнологичного производства в соответствии с Постановлением Правительства РФ № 218 от 09.04.2010 г.

\section{Конфликт интересов}

Авторы заявляют, что у них нет конфликта интересов.

\section{Список литературы}

[1] Лучинин В.В. Анализ кристаллов интегральных схем. С.-Пб: С.-ПбГЭТУ „ЛЭТИ“, 2016. 328 с.

[2] Димитров Д.Ц., Лучинин В.В., Мошников В.А., Панов М.Ф. // ЖТФ. 1999. Т. 69. Вып. 4. С. 129-131.

[3] Лучинин В.В., Панов М.Ф. // Микроэлектроника. 2002. Т. 31. Вып. 2. С. 129-134.

[4] Голоудина С.И., Лучинин В.В., Пасюта В.М., Криштаб М.Б., Панов М.Ф., Розанов В.В., Склизкова В.П., Кудрявцев В.В., Бакланов М.Р. // Нано- и микросистемная техника. 2015. Вып. 12 (149). С. 9-14.

[5] Nakashima S., Harima H. // J. Appl. Phys. 2004. Vol. 95. P. 3541-3546.

[6] Narita K., Hijikata Y., Yaguchi H. et al. // Jpn. J. Appl. Phys. 2004. Vol. 43. N 8A. P. 5151-5156.

[7] Панов М.Ф., Растегаев В.П., Корлякова С.А. // ЖТФ. 2014. T. 84. Вып. 8. С. 151-153.

[8] Уханов Ю.И. Оптические свойства полупроводников. М.: Наука, 1977. 368 с.

[9] Бочкин О.И., Брук В.А., Никифорова-Денисова С.Н. Механическая обработка полупроводниковых материалов. М.: Высшая школа, 1977. 152 с.

[10] Palik E.D. Handbook of optical constants of solids. San Diego: Academic, 1998. 999 p. 